\title{
The Role of the Labor Press in the Acculturation of Working-Class Immigrants 1880 s to 1930 s in the Atlantic Economies
}

\author{
J. H. M. Laslett \\ University of California, Los Angeles
}

This conference, on the Role of the Labor Press in the Acculturation of Working-Class Immigrants, took place in Frankfurt February 12-15, 1985. Attended by more than thirty participants from eleven different countries in Europe and North America, it was hosted by Dirk Hoerder of the University of Bremen. It was sponsored by the Volkswagen Foundation, which has for several years provided funding for the working-class Newspaper Preservation Project.

This project seeks to establish a comprehensive bibliography, as well as to set up microfilmed collections, of non-English labor newspapers in both the United States and Canada. It focuses particularly on the press of the new immigrant groups who came to north America between the 1880 s and the 1920 s, whose culture and way of life has until recently received less attention from historians than that of the older immigrant groups from northern and western Europe. Collaborative efforts to aid in this project, as well as other ethnic press collecting programs, were reported on at the beginning of the conference by Hoerder, by Rudolph Vecoli of the Immigration History Research Center at the University of Minnesota, and by Varpu Lindstrom-Best of York University in Canada. The consensus seemed to be that although a promising start had been made, much remains to be done, especially at a time when support funds for projects of this kind are drying up.

Methodological questions on how best to use as research tools both these papers and private letters written back home by immigrants occupied the first day of the meeting. Wolfgang Helbich of Bochum reported on his German immigrant letter-gathering project, in which he is analyzing more than 4,000 letters written back to Germany by emigrants to North America in the nineteenth century. As an offshoot of this, Ulrike Sommer, also of the University of Bochum, reviewed the content of some of the letters written by women, but found little on such matters as female emancipation or the suffrage. This find- 
ing contrasted markedly with the evidence presented by Maxine Seller, of the University of Buffalo, in her paper on the "women's interest" page of the heavily Jewish I.L.G.W.U. publication Justice, taken from the year 1919. She found extensive interest in advanced child-rearing practices, the sexual double standard, and other feminist issues. Still higher levels of consciousness were found by Varpu Lindstrom-Best and Allen Seager in their fascinating paper and slide presentation on the newspaper Toveritar, and the Finnish-Canadian women's movement in Oregon and in Western Canada at the time of the First World War. While these findings confirmed the well-known radicalism of both Jewish and Finnish immigrant communities, the German letters indicated the ongoing influence of patriarchy, or of male domination, among more traditional nineteenth-century immigrant groups.

These papers on gender and class, as well as several others like Gregory Kealey's analysis of the Canadian government's role in suppressing the east European ethnic press during the 1919 Red Scare, made use of immigrant newspapers primarily as a tool for writing the social history of particular ethnic groups at particular points in time. So, too, did several of the papers that dealt with issues of ethnicity and class. The most sophisticated of these was the one given by Nancy Green of Stanford, who showed how Der Idisher Arbayter, the organ of East European Jews in Paris, encouraged ghetto solidarity in the face of anti-Semitism during the period of the Dreyfus case, while seeking at the same time to raise the class consciousness of sweated Jewish laborers vis-à-vis their employers. Other papers, however, tried to link ethnic and class issues more openly with the question of acculturation. Some of these contributions, such as those made by Andrzej Porebski of Krakow, by Bruno Cartosio of Milan, and by Julianna Puskás of Budapest, did little more than delineate the sectarian politics of various foreign-language federations connected either with the S.L.P., the Communist Party of the United States, or the Socialists. But a number of others, particularly the paper read by Czech participant Frantisek Bielik, showed how the Slovakian press in America attempted to preserve the national heritage of its readers by reporting the news from home, and at the same time encouraged accomodation to American life by offering advice to immigrants on such matters as English-language classes, the policies of the two major political parties, and the operations of the American legal system.

A different approach to the question of acculturation was taken by contributors who dealt with the image of the United States put forward in European working-class newspapers by "birds of passage," or workers who travelled to North America and later returned to their home countries. One example of this was John Laslett's paper on Scottish emigrant miners of the 1860s and 1870s, some of whom went back and forth across the Atlantic several times before settling down in the American Midwest, and who offered insightful comments on America's attractiveness-or the lack of it-along the way. Two genera- 
tions later, according to the paper presented by Hannes Siegrist of the Free University of Berlin, immigrants did much of the same thing via the columns of their paper, the Schweizerische Technikerzeiting.

Yet little was done to follow up on the methodological questions that were raised on the first day by Sally Miller, of the University of the Pacific, who is preparing a wide-ranging book -in the form of essays by various authors-on the ethnic press in America. In her survey of working-class immigrant newspapers, which ranged from old immigrant papers like the New Yorker Zeiting to new immigrant journals like the Yugoslav Novi Svjet, Miller distinguished between three basic functions of this press: to inform the immigrant about the new world; to convey an ideological message, for example concerning what stand to take on political questions; and to represent the interests of particular ethnic groups in America's pluralist society as a whole.

Valuable though these distinctions were, they left many questions unanswered. For example, how influential was the ethnic press? How successful was it in combating, or in supplementing, the impact of the middle-class immigrant press in shaping the outlook of recently arrived factory workers? How did it respond to the influence of the powerful, and frequently conservative, Catholic church? Some light was thrown on these and other questions in the course of discussion by Rudolph Vecoli, among others. Vecoli argued that the influence of most ethnic working-class papers was considerably greater than their circulation figures (which are hard to obtain) might suggest. This derived from their role as the organizational nerve center of a wide range of social networks and cultural institutions, which varied from fraternal benefit societies to soup kitchens in times of depression.

No one conference could, of course, be expected to answer all of these questions. Most participants agreed that the meeting was highly informative, and that it should serve to stimulate further research in the many areas where the new immigrant history and the new social history interact. Yet, for this observer at least, there was one-but only one-major disappointment: the fact that despite its stated, and highly laudable, intention to examine the role of the working-class ethnic press in the context of the Atlantic economies as a whole (i.e., in the context of the intra-European movement of peoples, not just in that of intercontinental migration), very few papers addressed these issues. The exceptions were Laslett's paper on the Glasgow Sentinel, which reflected the mutual interaction between readers both in Scotland and in North America; and Claudius Riegler's fascinating presentation on the role of the Farende Svend (the Travelling Fellow) newspaper, which sought to inform, protect, and guide skilled Scandinavian craftsmen as they tramped from job to job all across early twentieth-century Europe. Since intercontinental (Pacific as well as Atlantic) migration is now recognized to be intimately linked to intraEuropean, and to individual national migration patterns, I would hope that some future conference will address these questions more directly. 
It is expected that the conference papers will be issued in a limited photocopy edition of about six hundred copies. Those wishing to purchase one, or to secure any further information about the meeting, should write to Dirk Hoerder, Fachbereich 10, Postfach 3304 40, D-2800 Bremen, West Germany. 